Council shall be lodged with the Registrar between the first day of January in any calendar year and the date which is four clear weeks after the meeting of the Councll which is first held after the name of the President for the next ensuing College year has become known, or (as the case may be) which is four clear weeks after that meeting of the Council which, in the case of a tie on the second ballot, determines the election of the President. *i.e. Written nominations, accompanied in each case by the nominee's written consent to stand for election, may be lodged with the Registrar. provided that each such nomination is supported in writing by not less than twelve Members of the College who are not members of the Council. An election by ballot shall be held in accordance with the provisions of the Regulations.

\title{
Approval of Doctors under Section 12 of the Mental Health Act (1983)
}

The College has recently been informed that the Department of Health has confirmed that Section 12 approved doctors may exercise their functions in relation to the Act in any part of England or Wales.

Although guidance had been issued in July limiting the geographical area in which Section 12 approved doctors could exercise their functions, this has now been reviewed.

The advice given by the Department of Health is that, as set out in Circular HSG (96)3, a doctor approved by any Health Authority (or before 1 April 1996, by any Regional Health Authority or by any District Health Authority in Wales) is approved for the purpose of section 12(2) of the Mental Health Act (1983), and may make recommendations under Part II of the Act (or give evidence to the Courts under Part III) in any part of England and Wales.

PROFESSOR C. THOMPSON, Registrar

\section{Meeting the mental health needs of adults with mild learning disabilities}

The report of the Joint Working Group of the Sections for Psychiatry of Mental Handicap and General Psychiatry on 'Meeting the mental health needs of adults with mild learning disabilities' was approved by the Council of the College on 18 June 1996.

The document examines the context of government policy, College policy, and issues arising from existing services. Characteristics of successful services are analysed, and detalled suggestions are given for creating solutions around key issues.

The recommendations have been summarised in order to give a concise message for purchasers:

- There is a need for specialisation to achieve high standards in services (including adherence to the legal and policy context, responstveness to the views of carers and patients, and other factors to improve outcome).

- Comprehensive coverage requires attention to potential gaps (arising from age and geography, diverse clinical needs and patterns of services).
- Specialist multidisciplinary mental health teams for people with learning disabilities are required (to enable people with mild learning disabilities and mental health problems to use ordinary health services wherever possible, and to provide help to meet needs which cannot be met through the ordinary range of services).

- Joint working should be promoted (between specialists in psychiatry of learning disability and other specialists). A task for specialists is to improve the ability of other, less specialised services to serve people with mild learning disabilities.

Working group members: Neill Simpson (Convenor), Nick Bouras, Greg O'Brien, Adrienne Regan, Allan Calvert, Desmond Dunleavy. Terry Nelson.

Copies of the full report are available from the Publications Department at the College.

NEILL SIMPSON 